\title{
Autosomal recessive cerebellar ataxia- epilepsy-intellectual disability syndrome due to TUD deficiency
}

INSERM

\section{Source}

INSERM. (1999). Orphanet: an online rare disease and orphan drug data base. Autosomal recessive cerebellar ataxia-epilepsy-intellectual disability syndrome due to TUD deficiency. ORPHA:404493

Autosomal recessive cerebellar ataxia-epilepsy-intellectual disability syndrome due to TUD deficiency is a rare, hereditary ataxia characterized by an early onset symptomatic generalized epilepsy, progressive cerebellar ataxia resulting in significant difficulties to walk or wheelchair dependency, and intellectual disability. 